\title{
Por uma antropologia ouriçada: práticas de extensão universitária, bordados e uma relação possível com a comunidade de Santo Amaro - BA
}

For a excited anthropology: university extension practices, and a possible relationship with the community of Santo Amaro - BA

Thaís Fernanda Salves de Brito

\section{(2) OpenEdition Journals}

Edição electrónica

URL: http://journals.openedition.org/aa/7678

DOI: $10.4000 /$ aa. 7678

ISSN: 2357-738X

Editora

Programa de Pós-Graduação em Antropologia Social (UnB)

\section{Edição impressa}

Paginação: 145-163

ISSN: 0102-4302

\section{Refêrencia eletrónica}

Thaís Fernanda Salves de Brito, «Por uma antropologia ouriçada: práticas de extensão universitária bordados e uma relação possível com a comunidade de Santo Amaro - BA», Anuário Antropológico [Online], v.46 n. 1 | 2021, posto online no dia 03 janeiro 2021, consultado o 27 abril 2021. URL: http:// journals.openedition.org/aa/7678; DOI: https://doi.org/10.4000/aa.7678

\section{(c) (i) (9)}

Anuário Antropológico is licensed under a Creative Commons Atribuição-Uso Não-Comercial-Proibição de realização de Obras Derivadas 4.0 International. 


\section{anuário antropológico}

\section{Por uma antropologia ouriçada: práticas de extensão universitária, bordados e uma relação possível com a comunidade de Santo Amaro - BA}

For an excited anthropology:

university extension practices, and a possible relationship with the community of

Santo Amaro - BA

DOI: https://doi.org/10.4000/aa.7678

Thaís Fernanda Salves de Brito • Universidade Federal do Recôncavo da Bahia - Brasil

Professora da Universidade Federal do Recôncavo da Bahia, doutora em Antropologia Social pela Universidade de São Paulo, mestre em Ciências Sociais pela Pontifícia Universidade Católica de São Paulo, graduada e licenciada em Ciências Sociais pela Universidade Estadual Paulista Júlio de Mesquita Filho. É coordenadora do Grupo de Pesquisa Mesclas e do Massapê - Programa de Educação Patrimonial.

Extensão universitária, a formação de um novo campus em uma universidade jovem e a descoberta de uma cidade do Recôncavo baiano são os temas deste artigo que apresenta uma espécie de sobreposição de experiência etnográfica, depoimento e reflexão sobre as possibilidades de um projeto de extensão, ligado à educação patrimonial e aos bordados. A prática extensionista fomenta, neste contexto, um ambiente relacional entre comunidade e universidade que se propõe a um diálogo de curiosidades, interesses e empenhos mútuos, além de novas perspectivas para uma pauta antropológica que trata de percepção dos espaços, redes de sociabilidade, modos de se relacionar a partir do ofício e da técnica.

Extensão Universitária. UFRB. Santo Amaro. Educação Patrimonial. Bordados.
University extension, the establishment of a new campus in a young university and the discovering of a city in the Recôncavo baiano are the issues of this essay which presents a sort of overlapping of ethnographic experience, testimony and reflections concerning the potential of an extension project, associated with heritage education program and embroideries. In this context, the extensionist practice promotes a relational ambience between the community and the university that aims a dialogue of curiosities, interests and mutual commitments, as well as new perspectives for an anthropological agenda that concerns the perceptions of spaces, networking, ways of interacting based on work and technique.

University extension. UFRB. Santo Amaro. Heritage Education Program. Embroideries. 


\section{Introdução}

Foi em 2014 que conheci Santo Amaro' ${ }^{1}$. Cheguei à cidade na última segunda-feira de janeiro, um ensolarado dia de "ressaca", após o "Domingo da Lavagem", um dos eventos que compõem sua festividade mais importante: A Festa da Purificação. Festa que é um marco na experiência sincrética afro-brasileira e que, há mais de 200 anos, carrega vida, folhas, cheiro de alfazema e fé nas quartinhas de barros de belíssimas baianas. Todos os anos, elas se reúnem na manhã do último domingo de janeiro na casa de Dona Canô ${ }^{2}$. Dali saem, acompanhadas de fogos, louvores e música, para lavar o adro da Matriz e para abençoar o seu povo que, em cortejo, celebra e se prepara para o novo ciclo a ser iniciado com a procissão de Nossa Senhora, no dia 2 de fevereiro.

Ao chegar em Santo Amaro, trazia em minha bagagem uma espécie de cartografia imaginada combinada por narrativas sobre resistência histórica a favor da independência, luta de grupos abolicionistas e estratégias de liberdade dos escravos (Fraga, 2014). Esse quadro continha, ainda, alguns fragmentos do cotidiano de um Brasil profundo, certas personagens da literatura, muita música, enfim, um caleidoscópio de percepções recortado pela influência poética dos seus filhos ilustres: cronistas, artistas, engenheiros, políticos, enfim, figuras que conhecia das canções, das esculturas, dos livros, das placas das ruas ${ }^{3}$ e que me faziam pensar que eu deveria estar diante de um espaço singular.

A beleza do povo, suas expressões culturais e essa imaginação sobre o lugar, no entanto, contrastavam com uma espécie de cansaço e de tristeza que se evidenciava conforme caminhava por ruas santamarenses, percepção similar à que narra Marengo (2008). A arquitetura da cidade, possivelmente, tenha me levado a esta sensação intrincada: composta por edificações pouco preservadas que remontam a tempos prósperos da colonização, algumas ruínas imponentes criando efeito de decadência, somadas a um sem fim de pequenos prédios, construídos com criatividade - a partir da necessidade de ocupar espaços centrais com moradias plurifamiliares - cuja lógica não parece estar atrelada a quaisquer movimentos arquitetônicos (algo similar ao que D’Ambrosio (2007) chama de "arquitetura espontânea"4). Enfim, caminhando pelas ruas e conversando com as pessoas, fui percebendo que estava diante de uma cidade estruturada por camadas, composições, movimentos e criatividade. Se a "arquitetura é a cena fixa das vicissitudes do homem, carregada de sentimentos de gerações, de acontecimentos públicos, de tragédias privadas, de fatos novos e antigos” (Rossi, 2001, p. 3), intuía que essa terra de massapê, sol intenso, cana doce, pescadores e marisqueiras se apresentava como uma "cidade-laboratório".

Tem se tornado comum a expressão "cidade-laboratório". São os setores dedicados às tecnologias emergentes que vêm propagando esse conceito. De acordo com esses grupos, é esperada a criação de cidades cujos processos de produção, circulação, consumo sejam modelados pela ciência e pelas tecnologias de ponta. A invenção desses espaços busca promover soluções de inovação tecnológica para a vida cotidiana, desde que aliados a um suposto desenvolvimento econômico e
1 Este artigo foi produzido durante o pós-doutorado junto ao Departamento de Antropologia da Universidade de São Paulo, sobre a supervisão de Fernanda Areas Peixoto, interlocutora preciosa. Agradeço a Jorge Luis Mattar Villela, cuja interlocução sobre o lugar das novas universidades foi essencial para a produção deste artigo; a Sylvia Caiuby Novaes, quem me animou no investimento na extensão; a; e a Lorena Penna, que tem me ajudado a refletir sobre a experiência com extensão e sobre a ideia de laboratório.

2 Claudionor Viana Teles Veloso, falecida em 25 de dezembro de 2012, aos 105 anos. Mesmo após sua morte, é o seu quintal quem segue recebendo este cortejo em festa. 3 Alguns santamarenses a que faço, muito rapidamente, alusão, são os músicos Assis Valente, Caetano Veloso, Maria Bethania, Edith do Prato, Roberto Mendes, Tia Ciata; os poetas Jorge Portugal e Mabel Veloso; o artista plástico Emanoel Araújo, o capoeirista Besouro; os políticos Conselheiro Saraiva, Marquês de Abrantes, Barão de Sergy, Marquês de Santo Amaro, Pedro Lago, o engenheiro Teodoro Sampaio, os médicos José Silveira e Yvan Argolo.

4 "A arquitetura chamada 'espontânea' oferece soluções geralmente surpreendentes, fora dos padrões tradicionais e com materiais pouco convencionais. Em comum, esses 'arquitetos' têm, geralmente, a falta de formação técnica ou acadêmica e o uso, quase indefinido e infinito de adornos, objetos, ladrilhos e cacos que vão sendo somados à obra" (D’Ambrosio, 2007, online). 
social. Contudo, não é este o sentido do termo que me inspira aqui. Olhar Santo Amaro como uma "cidade laboratório" é seguir as pistas de Rossi (2001) e entender a cidade como um "fato social", uma vez que orientada pelos meus interesses antropológicos acerca das sociabilidades, das lógicas de poder, dos processos de saber-fazer, dos modelos inventivos e das experiências da cultura estava diante de um lugar que, prontamente, pareceu múltiplo.

Meses depois, eu me tornei moradora desta “cidade-laboratório". E, ao mesmo tempo, tornei-me experimento. Recém-chegada para trabalhar em um Campus Universitário que havia sigo inaugurado para ofertar um bacharelado interdisciplinar que, também, era experimental. Como migrante e pesquisadora, definitivamente não poderia ser uma mera observadora da vida social; como professora e servidora pública, não me cabia ser uma "peça passiva e/ou um ator numa situação estratégico-política" (Alves, 1980, p. 75). Eu ansiava participar de um contexto de transformação. Para isso, era preciso me integrar à vida da comunidade e me predispor a me transformar, antes de qualquer coisa.

Entretanto, a sala de aula ou a opção em seguir uma investigação estruturada, ainda que promissores, não me levariam a lugar desejado e ainda manteriam uma relação assimétrica. Para romper com as resistências possíveis, era preciso uma abertura radical, um outro tipo de engajamento. Ao conhecer a realidade da universidade de que, agora, eu fazia parte, percebi que havia um caminho possível para me aproximar deste desejo: a extensão universitária.

Cidades pequenas e médias recebendo universidades é uma experiência um tanto recente no contexto baiano, salvo uma ou outra instituição ligadas aos grupos de elite. No entanto, o que temos experimentado com o processo de interiorização do ensino superior pode alterar, até mesmo, a nossa perspectiva sobre inclusão social e produção de conhecimento, atuando em contextos de supressão de direitos básicos e vulnerabilidade econômica, como veremos a seguir.

Este artigo reflete uma espécie de sobreposição de experiência etnográfica junto à tentativa de historicização da formação de um novo campus universitário, realizada pela perspectiva de uma antropóloga e cunhada por meio de um projeto de extensão universitária em parceria com mulheres de um bairro popular de Santo Amaro. Para isso, três partes organizam esta escrita, somada à breve introdução. Em "'Para ser do Recôncavo tem que estar em Santo Amaro': a luta de uma cidade pela sua universidade", busco narrar algumas das características da universidade, junto à descoberta de um bairro, previsto para receber o campus. Posteriormente, em "Bordando a cidade e as Bordadeiras da Ilha: um projeto de extensão", apresento o projeto de extensão que, neste artigo, funcionará, igualmente, como guia para algumas reflexões sobre prática extensionista e para perceber como a comunidade nos ensina a repensar certos conceitos. Por fim, algumas considerações finais. 


\section{Para ser do Recôncavo tem que estar em Santo Amaro: a luta de uma cidade pela sua universidade}

Cerca de quatro meses depois, retornei à cidade. Era 13 de maio. Santo Amaro me recebeu com outra de suas festas surpreendentes: Bembé do Mercado. Narrativas populares descrevem que, um ano após a abolição, muitos eventos cívicos comemoraram o feito; contudo, estas festividades não incluíam os libertos como protagonistas das celebrações (Fraga, 2014). Foi, então que João de Obá, sacerdote de Candomblé, junto com os pescadores e com o Povo de Santo, saíram da zona periférica e foram até a região central onde vivia uma pequena burguesia nascente, funcionários da Estrada de Ferro e servidores públicos do Estado. Ali, na ponte do Xaréu, às beiras do Rio Subaé, eles tocaram seus tambores e dançaram durante três dias e três noites celebrando, a seu modo, o primeiro ano da liberdade. Ao final da festa, entregaram um presente para Mãe D'Água, agradecendo a sobrevivência e a liberdade, prestando culto aos ancestrais e aos orixás, assumindo geográfica e politicamente seu espaço como povo de fé e como cidadãos (Iphan, 2019).

Naquele 13 de maio de 2014, voltei ao Recôncavo para organizar minha transferência para a cidade, após ingresso, como professora, na Universidade Federal do Recôncavo da Bahia (UFRB). Criada em 2005, esta jovem universidade foi estruturada pelo princípio da multicampia, com o objetivo de atender as várias localidades do Recôncavo Baiano, considerando suas características e necessidades. A UFRB nasceu do desmembramento do tradicional campus dedicado aos estudos da

agronomia e veterinária da Universidade Federal da Bahia, anteriormente, o elitista Imperial Instituto Baiano de Agricultura (IIBA), fundado em $1^{\circ}$ de novembro de 1859 por D. Pedro II, para atender ao "agronegócio" colonial. Até 2013, operou em quatro campi: Cruz das Almas (Escola de Agronomia), Cachoeira (dedicado às Ciências Sociais, Artes e Humanidades), Santo Antônio de Jesus (Ciências da Saúde) e Amargosa (Centro de Formação de Professores). Posteriormente, ampliou-se no Campus Universitário de Feira de Santana (Engenharias).

A UFRB é fruto do Programa de Reestruturação e Expansão das Universidades Federais (Reuni), instituído pelo Decreto $n^{\circ}$ 6.096, de 24 de abril de 2007, como parte das ações que integram o Plano de Desenvolvimento da Educação (PDE). O Reuni ampliou o acesso e a permanência na educação superior. Para isso, foi tomada uma série de medidas para retomar o crescimento do ensino superior público, criando condições para que as universidades federais promovessem a expansão física, acadêmica e pedagógica da rede federal de educação superior. As ações do programa contemplavam o aumento de vagas nos cursos de graduação, a interiorização do ensino, a ampliação da oferta de cursos noturnos, a implantação de políticas afirmativas, a promoção de inovações pedagógicas e o combate à evasão.

O Reuni e, por consequência, a UFRB compreendiam um novo propósito para as universidades que, além de ser lugar de ensino e de pesquisa de ponta, configuram-se como possibilidade real de redução de desigualdades sociais. Vale destacar que, neste contexto de imaginação de uma universidade acessível e coerente com 
as realidades locais, incentivou-se a criação de Bacharelados Interdisciplinares, fomentando propostas mais amplas de arquitetura curricular em nível de graduação. A abertura deste espectro e a ampliação da oferta de vagas nas formações de graduação fomentaram oportunidades para uma mudança expressiva do perfil estudantil e uma inovação curricular.

Partindo desta característica experimental, em 2014 foi inaugurado o Centro de Cultura, Linguagens e Tecnologias (Cecult), e, com ele, o Bacharelado Interdisciplinar em Cultura, Linguagens e Tecnologias (Bicult). Os bacharelados interdisciplinares são cursos de três anos que se caracterizam por uma matriz curricular constituída em módulos. Os estudantes têm matérias obrigatórias destinadas à formação cultural e aos espaços de interconhecimento. Além desta base, o curso conta com um ciclo de componentes curriculares voltados ao itinerário formativo, combinados com matérias optativas que levam às terminalidades oferecidas, a saber: Curso Superior Tecnológico em Tecnologias do Espetáculo (dedica-se às áreas de Cenografia, Figurino, Iluminação e Caracterização), Licenciatura em Música Popular Brasileira, Curso Superior Tecnológico em Produção Musical, Licenciatura Interdisciplinar em Artes, Curso Superior Tecnológico em Política e Gestão Cultural e Design Digital (ainda em fase de elaboração). Enfim, do campus ao curso elegido, tudo era novidade.

Além da tradição com as festas, com as manifestações populares e com a proeminência de alguns artistas de projeção internacional, há uma peculiaridade interessante sobre o campus de Santo Amaro. Este projeto se executou por meio de pressão popular e do movimento "Para ser do Recôncavo tem que estar em Santo Amaro". A UFRB em Santo Amaro é o resultado de desejos antigos. Em 14 de junho de 1822, cidadãos ilustres da cidade se reuniram na Câmara de Santo Amaro, na Sala de Vereança, a fim de conceber um documento para a Metrópole (Portugal). Esse documento apresentava uma radicalização do movimento de Independência política do Brasil. O registro da reunião - conhecida como Ata da Vereança - trouxe algo de fundamental importância para a implantação da UFRB e, principalmente, para a criação do Campus de Santo Amaro. Além da luta pela independência e da militância pela centralização de um Governo do Brasil - Imperial e Liberal -, essa ata registrou o pedido da instituição do Exército Nacional, da criação do Banco Estatal, da consolidação do Corpo Diplomático e do Tribunal Supremo de Justiça, além de um petição peculiar: "que se funde quanto antes uma Universidade em logar que mais conveniente for" (Pedreira, 1973, p. 2).

O movimento "Para ser do Recôncavo tem que estar em Santo Amaro" foi criado em 2008, por meio de uma mobilização coletiva, amparado na ata de 1822. Desejos antigos, políticas afirmativas e luta do movimento negro organizaram cidadãos de Santo Amaro para trazer a UFRB e para debater sobre a constituição desse espaço. Segundo contam alguns participantes do movimento, houve momentos de tensão porque um grupo de cidadãos ilustres da cidade desejava a oferta de cursos ligados às carreiras mais tradicionais, como direito e administração de empresas. No entanto, outros, ao entender a cidade como um lugar de "Cultura" e fonte de conhecimento, foram parceiros da proposta do Cecult e de 
seu bacharelado interdisciplinar. Roberto Mendes, músico, compositor e membro deste movimento afirmou que:

\begin{abstract}
Santo Amaro sempre esteve no pensamento nacional, Santo Amaro é uma encruzilhada, é um povoado de 1557, Santo Amaro não é um município qualquer, pois se tornou vila em 1727 e se tornou cidade em 1837, século XIX. Então você vai acumulando esse conhecimento e chega até hoje, e imaginar que dentro dessa universidade vai ser discutido todo esse trajeto histórico, sua vida do século XVI até hoje, eu acho que vai valer a pena. Santo Amaro não pode ser terra de artistas, Santo Amaro é uma terra de conhecimento (Mendes, 2013).
\end{abstract}

É interessante notar como que este movimento pela presença da UFRB não entendia a universidade como a autoridade máxima ou unilateral de um saber, mas como um lugar de intercâmbio. A cidade, em si, se assume como terra de arte e de saber; a universidade, por sua vez, poderia ampliar e profissionalizar este potencial. Quanto a mim, poder participar da criação de um campus, neste local pulsante e com amparo da comunidade, me soava como uma realidade quase ideal.

Nos meses que se seguiram, trabalhava muito. Mais do que tarefas, interessava-me apreender uma universidade pública jovem em um campus que passava a existir. Uma antropóloga - professora e pesquisadora - agora, também, burocrata, aventurando-se a decifrar qual o lugar da Antropologia em um curso experimental com interesses que eu sequer tinha domínio. Conforme passava o tempo, o deslumbramento inicial ficava nas gavetas do cotidiano e, com os dias, nem sabia mais quem eu era, quanto mais quem era nativo. As questões regionais - e, talvez, étnicas - começaram a me impactar e a causar um certo sofrimento para além do que estava preparada.

No final daquele segundo semestre, iniciamos uma investigação ${ }^{5}$ sobre a apropriação da antiga fábrica Tarzan, localizada junto ao bairro Ideal e próxima ao bairro Ilha do Dendê. Atualmente em ruínas, naquele espaço funcionou a primeira metalúrgica do Nordeste e, antes, a Destilaria Meleirinha. Esta localidade foi cedida, pela prefeitura, para construção do campus definitivo do Cecult, acompanhado de um centro cultural em anexo. Este projeto seria realizado juntamente com o IPHAN e contemplado pelo Programa de Aceleração do Crescimento (PAC), voltado às cidades históricas. Naquele momento, as ruínas representavam simbolicamente um caminho a reconstruir, uma nova história a contar a partir das camadas de cidade que Santo Amaro nos revela e, principalmente, nos apontavam para um espaço de pertencimento e de atuação.

As impressionantes ruínas da siderúrgica ficam na extremidade do eixo urbano da cidade em uma região que guarda uma série de especificidades. Das roças à ocupação desordenada do espaço, soma-se o sucessivo abandono de vários governos. Tradicionalmente composta por comunidade pesqueira e marisqueira ${ }^{6}$, é provável que sua ocupação tenha sido formada por remanescentes de escravos que ali foram viver logo após a abolição, pela proximidade do rio e pelas ter-
5 "Ruínas Tarzan e seus fluxos: um estudo sobre apropriação do espaço em área fronteiriça", em parceria com o prof. Roney Gusmão e com as estudantes (hoje graduadas) Tainara Freitas e Raíssa Lima. 6 Esta região de manguezais, outrora, fornecia pescados, caranguejos e mariscos (ainda hoje os fornece, com baixa produção, voltada, essencialmente, para consumo local). Para se ter uma ideia da antiga produção de pescados e crustáceos na cidade, veja a publicação do IBGE de 1968 (suprimi dados financeiros): “A pesca, em 1965, ocupou 750 pescadores (520 maiores de 18 anos), não colonizados, equipados com 175 embarcações, 20 redes de arrasto, 15 de espera e 23 armadilhas fixas. A produção de pescado, quase toda do mar, alcançou, em 1966, 407,7 toneladas (...). Desses totais, 289,0 toneladas (...) referem-se aos crustáceos. Predomina o camarão, com $95 \mathrm{t}$ (...), entre os crustáceos; e a arraia, com $12 \mathrm{t}$, a tainha, com 6,5 t (...), o bicudo, com 5,2 t (...), e o minor, com $11,0 \mathrm{t}$ (...), entre os peixes" (IBGE, 1968, p. 10). 
ras do fértil massapê $\hat{e}^{7}$, garantindo-lhes cultivo de dendê e muitas frutas. O final das atividades da Siderúrgica Tarzan, na década de 1980, acelerou o processo de empobrecimento destes bairros, ampliando a situação de vulnerabilidade. Essa situação tornou-se ainda mais grave com a poluição do rio Subaé. Eis uma boa definição do bairro:

Ilha do Dendê é um bairro periférico de Santo Amaro, situado na confluência do rio Traripe com o rio Subaé, abriga uma comunidade de aproximadamente 4.000 pessoas e apresenta particularidades na ocupação desordenada do solo e graves problemas ambientais.

Encravado nas margens do mangue que compõe o sistema estuarino do rio Subaé e receptor de toda poluição que afeta a Bacia - efluentes industriais, esgotos domésticos, agrotóxicos utilizados nos canaviais e nas culturas de hortaliças. A população aí residente é a mais atingida pelos impactos ambientais. Destacamos o acentuado assoreamento do rio Traripe e a destruição dos manguezais próximos, refletindo na redução de vida, especialmente de mariscos, importante fonte de renda e alimentação da comunidade.

Às condições particulares de sua localização, deficiência na infraestrutura urbana, acrescem-se o baixo nível social-econômico da comunidade, aliado ao baixo grau de escolaridade que limitam as iniciativas quanto as mudanças de atitudes (Sacramento et al., 1999, p. 13).

Se não bastassem os recorrentes abandonos estatais, as agudas questões sociais e os graves impactos da poluição ambiental, este lugar é, ao mesmo tempo, estigmatizado pelo preconceito e por uma projeção da ideia de que se trata de uma área violenta. "A Ilha do Dendê sempre foi o 'lugar dos pretos' da cidade de Santo Amaro", disse-me uma moradora da cidade quando me contou sobre o desespero de sua mãe ao ficar sabendo que "a moça que cuidava dela" (babá), moradora do bairro em questão, precisou ir até a sua casa e a levou consigo. Quando ouvi isso, imediatamente estranhei. Para mim, que venho de fora e que sou não-negra, Santo Amaro é uma cidade efetivamente negra. Meu olhar externo e destreinado não via, até aquele momento, uma distinção racial nos espaços ocupados da cidade. Mas eles existem.

A despeito dos estigmas, este bairro guarda, ainda, efetivos lugares de resistência. É um reduto importante do samba de roda, onde vive a sambadeira Maria Eunice Martins Luz, Dona Nicinha, mulher de reconhecido saber, guardiã do samba e que há décadas permanece à frente do Grupo Raízes de Santo Amaro com cerca de 16 músicos entre tocadores de atabaque, pandeiro, reco-reco, agogô, tamborim e maraca que, junto com as sambadeiras - mulheres que, vestidas de baiana, com seus sapateados miudinhos e requebrados característicos, seguem criando, recriando e construindo sua importância musical que transcende aos meios culturais locais.
7 Massapê é um tipo de solo comum em regiões litorâneas do Nordeste brasileiro. Caracteriza-se por solo de tom escuro, textura argilosa, boa fertilidade, com calcário e magnésio. 
Foi, a partir dali, que Paulino Aluísio de Andrade, o Mestre Popó do Maculelê, rememorando histórias da época da escravidão, na década de 1940, criou sua trupe e passou a difundir essa espécie de luta marcial ritmada, circular, acompanhada por uma dupla de bastão roliço de madeira (grimas) e pelo som dos atabaques, berimbaus e viola.

Este lugar guarda, ainda, o Terreiro de Pai Pote: Ilê Axé Oju Onirê. Esta casa de Candomblé e Ponto de Cultura tem organizado, entre outras coisas, o Bembé do Mercado (celebração que, em 2019, recebeu o título de Patrimônio Imaterial pelo Instituto do Patrimônio Histórico e Artístico Nacional) e a "Lavagem da Madeleine", que, nos últimos 18 anos, vem levando brasileiros radicados na França e demais simpatizantes da religião em cortejo pelo Boulevard Saint Martin, Paris ${ }^{8}$.

Afinal, ao redor do lugar que seria construído o nosso novo campus e considerando, de um lado, esses espaços de resistência ligados às manifestações culturais afro-brasileiras e, do outro, os recorrentes estigmas que cercam a realidade daquele espaço, o que realmente me chamou a atenção, naquele momento, foram os fortes laços de vizinhança e de protagonismo feminino, que percebia de modo nítido. Ali eram explícitas as estreitas relações de solidariedade e de parceria entre mulheres, similar ao que Agier (2011) havia observado com os bairros populares de Salvador. Percebi, então, que gostaria, de alguma forma, de compartilhar daquele universo.

\section{Bordando a cidade e as Bordadeiras da llha: um projeto de extensão}

Meus interesses de pesquisa se voltam à investigação da produção artesanal de bordados. Acredito que os bordados têm sido uma forma interessante de trabalho, além de ser uma ferramenta de expressão estética, de interpretação do mundo e de ação política, principalmente realizada pelas mulheres. É um saber-fazer com caráter transformacional, gentil e pacificador, o que em nada significa uma prática não assertiva (Corbett, 2017). Além do mais, qualquer pessoa pode bordar, independentemente de sua religião, geração, classe social.

Conforme fui conhecendo a cidade, e principalmente por meio de minhas alunas, soube que em Santo Amaro se produziram bordados durante muito tempo, seja nas casas mais abastadas ou nas menos privilegiadas. Apesar de não ter cunho comercial, o bordado foi uma atividade representativa até meados de 1970 - como sugerem conversas informais - porém, atualmente, ele tem sido pouquíssimo praticado (Brito, 2016), apesar de ser muito popular, principalmente por conta da indumentária do Candomblé.

Um exemplo interessante de inserção do bordado na cidade pode ser revelado pelo Recolhimento dos Humildes. Nesse local, durante o século XIX e meados do século XX, funcionou um centro de educação feminina para abrigar órfãs, escravas, viúvas, ou até mesmo filhas de senhores de engenho dedicadas à oração, ao trabalho manual e à educação (Lose; Mazzoni, 2016). Como um centro de educação para as mulheres, os trabalhos manuais eram prioridade naquele período
8 "Lavagem da Madeleine atinge a maioridade e cria a ala Mulheres da Resistência". Jornal RFI. Publicado em: 08/09/2019. Disponível em: https://www.rfi. $\mathrm{fr} / \mathrm{br} /$ franca/20190908-lavagem-da-madeleine-atinge-maioridade-e-cria-ala-mulheres-da-resistencia. Acesso em: 12 jul. 2020. 
e precisavam ser executados com precisão, formando, simultaneamente, boas donas de casa e/ou trabalhadoras (Brito, 2016). Nos dias de hoje, o espaço abriga um educandário e um externato para acompanhamento escolar de meninas em situação de vulnerabilidade social, além de um Museu (de título homônimo) dedicado às artes sacras que foi reaberto em 2019 e tem promovido ações em torno das linguagens artísticas, em consonância com os interesses da comunidade.

No imaginário da cidade, todavia, corre um lamento sobre o rigor a que eram submetidas as jovens, muitas vezes obrigadas a realizar as atividades de linhas e agulhas a contragosto. Por outro lado, os conjuntos de amostra de bordados, por exemplo, revelam uma variedade de técnicas e de motivos que testemunham uma prática disciplinada, apuro estético e processo cuidadoso de transmissão de saber. Hoje, ainda que estes registros estejam guardados em algumas gavetas, as memórias sobre o bordar permanecem nas lembranças e na habilidade para o aprendizado. Deste modo, percebi que os bordados, ainda que escondidos, existem e que poderiam ser um caminho de aproximação entre mulheres; afinal, trata-se de algo acessível, ligado à socialização feminina e que poderia ser revisto, talvez, ressignificado.

Outro dos meus empenhos acadêmicos frequentes se refere à questão do patrimônio. Cotidianamente, Santo Amaro me provocava a pensar sobre este tema, seja na sua configuração material - a arquitetura - ou imaterial - suas expressões. Contudo, minha sensação era estar um campo minado: de um lado, uma série de pesquisadores há muito tempo envolvidos com as experiências culturais do Recôncavo; do outro, o Estado e suas questões de identidade e de legitimação decidindo sobre que é ou não patrimônio.

Eu queria tentar descobrir, no entanto, como o patrimônio era entendido pelo ponto de vista do pessoal da Ilha do Dendê. O meu olhar treinado me levava ao samba, ao maculelê, ao candomblé, às ruínas, mas não tinha ideia se, na rotina do lugar, essas experiências eram consideradas como um "patrimônio". Além disso, julgava importante refletir sobre este tema, uma vez que o Cecult versava sobre questões relacionadas à produção e à reprodução da cultura. Ademais, pensava como a questão patrimonial e as pessoas do bairro se relacionariam com a presença da UFRB naquele espaço: uma nova personagem que chegaria em situação privilegiada, possivelmente impactando seus processos de memória e de socialização através da ocupação do espaço.

Desafiei-me, então, a refletir sobre a temática do patrimônio, sem me colocar entre relações já conflituosas. Recorri, então, aos bordados como ferramenta de aproximação. Mulheres como protagonistas em um bairro com múltiplas carências, uma cidade com uma história de experiência estética feminina por meio dos bordados, somados a uma pulsante vida cultural se revelaram como ingredientes perfeitos para um projeto de Educação Patrimonial - e talvez de intervenção social.

Deste modo, após a elaboração, formalização e aprovação do projeto "Bordando a Cidade", no âmbito da UFRB, uma equipe de investigação e de prática extensionista foi composta com a participação de três alunas bolsistas do Programa de Permanência Qualificada (PPQ-UFRB) ${ }^{9}$. Neste primeiro momento, entre abril 
e agosto de 2015, as técnicas do bordado, outrora ensinadas para as meninas santamarenses, foram investigadas pela equipe, e a partir daí selecionamos técnicas mais simples e populares para reproduzir em grupo.

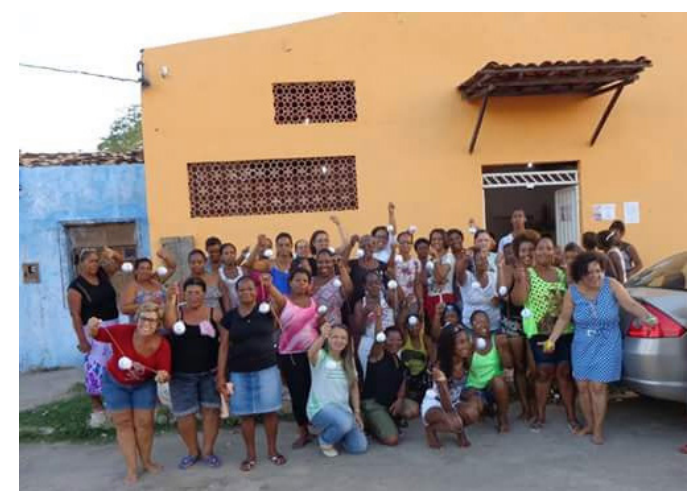

A segunda fase do projeto se iniciou em setembro de 2015, quando ocorreu a Oficina "Bola da Felicidade", ministrada por Teresa Barreto, em parceria com Programa de Extensão Universitária da Universidade de Campinas. Usando meias e plumas, montamos uma bola que ia sendo produzida com os pontos de bordado que as participantes ainda lembravam, sendo conduzida por Teresa, alguém com muita experiência neste tipo de atuação. A partir da bola de meia, as mulheres eram provocadas a bordar uma narrativa sobre sua vida: um símbolo que representasse os seus pais, algo que contasse sobre o lugar de origem, como elas entendiam os afetos. O que parecia soar como uma espécie de terapia ocupacional se tornou um amuleto que, por um bom tempo, nos acompanhou e nos serviu para lembrar quem elas eram e quais foram suas lembranças.

Foi interessante notar que muitas daquelas bolas exprimiam em desenhos histórias da infância e sobre a Ilha, obviamente por uma perspectiva afetiva. As bolas trouxeram uma experiência única com o lugar e com a natureza daquele espaço. Apesar do bairro, superficialmente, trazer uma arquitetura formada de ocupações não regulamentadas, ele também é feito de ruas, árvores, flores e rios: uma cartografia do lugar que eu apenas comecei a perceber depois dos bordados que as mulheres produziram.

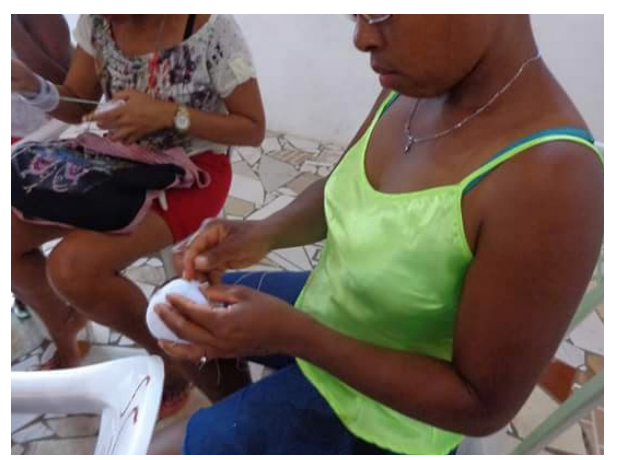

A partir desse encontro e em parceria com a Cáritas, ligada à Igreja Nossa Senhora do Rosário, passamos a promover oficinas no Centro São Cristovão na Ilha do Dendê. Essas oficinas incluíram aulas de técnicas de bordado e de educação patrimonial - com a participação de Moari Castro, museólogo (servidor técnico
9 O Programa de Permanência Qualificada (PPQ) é parte do conjunto de políticas que visam garantir a permanência dos estudantes beneficiários dos Programas de Políticas Afirmativas da UFRB, por meio de participação em projetos de extensão e atividades de iniciação científica, relacionadas à sua área de formação e ao desenvolvimento regional.

Imagem 1: Oficina Bola da Felicidade

Imagem 2: Bola da Felicidade 
da UFRB). Intercalávamos as oficinas periodicamente e, por meio deste "jogo" de técnicas do fazer e da percepção sobre patrimônio material e imaterial, começamos a criar repertórios para desenvolvimento de produtos que pudessem narrar elementos da cultura da região pelo ponto de vista das participantes da oficina.

As oficinas de bordado foram ministradas por mim, por uma das alunas que já sabia bordar e outra que conhecia alguns princípios básicos de costura. Porém, nosso conhecimento sobre as técnicas de bordado era ínfimo. Na verdade, ajudávamos umas às outras, contávamos com os registros da memória, com muitos manuais e tutoriais do Youtube e com a parceria de uma das freiras que atuavam junto à comunidade local. Naquelas oficinas aprendemos os pontos básicos de bordado, além de técnicas de arremate, corte de tecido, combinação de cores e de estilos de bordado, ainda sem nenhum destino específico para as peças ou motivos pré-determinados. Depois de algumas semanas, decidimos bordar um pano de prato com uma árvore que representasse a vida de cada uma. Mais do que uma aplicação das novas técnicas aprendidas e o treino da combinação das cores, interessava-nos coletar novas histórias sobre a Ilha do Dendê, já que a natureza tinha sido uma referência constante no primeiro exercício.

Durante duas semanas nos dedicamos a esse pano, e no encontro subsequente decidimos que era chegado o tempo de termos um nome e uma logomarca, afinal já éramos um grupo e já tínhamos um objetivo comum: bordar as coisas da Ilha do Dendê. Bordar a árvore no pano de prato serviu como um caminho para pensar no que o grupo estava se tornando e quais eram as contribuições originais de cada uma das participantes. Foi a partir destes exercícios, e considerando a cartografia afetiva e as particularidades do lugar que pareciam ser mais recorrentes nas narrativas das bordadeiras, que destacamos a presença dos dendezeiros. A partir daí, esboçamos coletivamente a logomarca, posteriormente executada pelo professor e designer Walter Mariano: é um dendezeiro, mas o caule da árvore é uma agulha, e a linha que a perpassa dá forma ao morro estilizado que víamos exatamente do lugar onde bordávamos, lá no começo do projeto. A logomarca é, portanto, cenário, proposta e memória, tanto de nosso começo quanto daquele lugar.

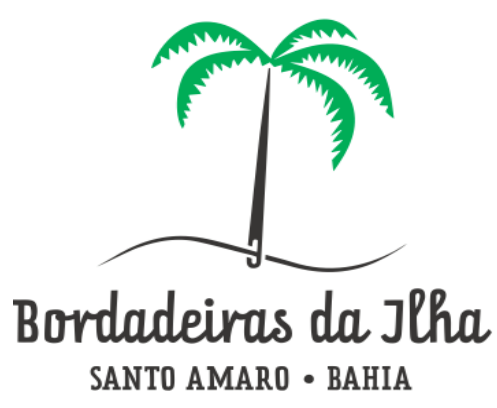

Uma vez que tínhamos histórias compartilhadas, um nome e um desenho que nos representasse, entendemos que já era chegado o momento de contar sobre a cidade. Nesta ocasião, algumas oficinas sobre patrimônio já haviam sido ministradas. Além das referências da natureza daquele espaço, algumas expres-
Imagem 3: Logo Bordadeiras da llha 
sões culturais santamarenses, inclusive aquelas ligadas ao bairro em questão, se fizeram presentes nos encontros, nas conversas e nos exercícios para pensarmos sobre o que deveríamos destacar.

Uma das bolsistas apresentou um bordado sobre a capoeira, outra propôs desenhos de baianas e de pescadores. Algumas das bordadeiras aceitaram o desafio de bordar essas cenas, transformando-as em produtos que foram muito bem aceitos entre os turistas que visitaram a Festa da Purificação no ano seguinte, em 2017. Contudo, entre todas as celebrações, expressões artísticas, culturais e a gastronomia ${ }^{10}$, foi a Festa de São João que surgiu de modo espontâneo entre o grupo e se revelou uma unanimidade. Por isso, resolvemos bordar uma cena dos festejos de São João como o nosso primeiro produto para venda. A cena era simples: uma noite singela, com fogueira e bandeirolas. Usamos o tecido jeans como base para os bordados e algodão xadrez como verso das peças para produzir os jogos americanos. Cerca de 40 peças foram bordadas em cerca de duas semanas por umas 15 bordadeiras. Todas as peças foram vendidas para as festividades juninas de 2016 .

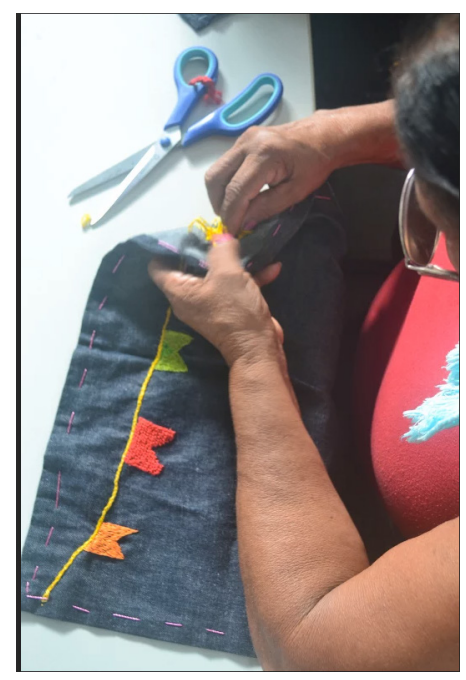

Essas experiências inaugurais e o sucesso com as vendas dos jogos americanos nos levaram a outra configuração: as oficinas e as reflexões sobre o patrimônio eram fundamentais, mas poderíamos, ao mesmo tempo, gerar trabalho e renda. Esta era uma questão importante para algumas daquelas mulheres e, no final de 2016, passamos a discutir a possibilidade do grupo inaugurar uma nova fase: organizar a Associação Bordadeiras da Ilha com aquelas que se mostravam predispostas a um ofício. Com isso, no início de 2017, percebemos que o número de participantes havia reduzido, entretanto, o comprometimento das bordadeiras havia aumentado. Elas começaram a participar de alguns eventos na universidade - algo, até então, inimaginável -, criaram coleções temáticas, começaram a aceitar encomendas. Toda essa movimentação trouxe à tona características importantes que aquelas mulheres não pareciam ter consciência sobre si mesmas: apuro estético, tino comercial, agilidade e disciplina, predicados essenciais para uma boa bordadeira. Isso, talvez, tenha sido o melhor de nossa contribuição e, não por acaso, aponta para algumas das categorias que venho tentando entender nas minhas investidas antropológicas pelo percurso dos bordados.
10 A gastronomia em Santo Amaro é paixão, fonte de conhecimento e de competição. Uma das atividades que as mulheres precisaram realizar, após uma das oficinas de educação patrimonial, foi dirigir-se até a feira (Mercado de Santo Amaro) e se atentar aos produtos com estranhamento, a partir de um posicionamento distinto daquele que se tinha no cotidiano, inclusive, o desafio era observar os produtos vendidos no local como se eles fosse uma peça de arte. Assim sendo, deveriam prestar atenção ao formato de legumes, verduras, temperos, assim como se manter atentas à cor, à combinação e à composição dos tabuleiros. Todas narraram uma experiência incrível de afinar a percepção tanto sobre o mercado quanto sobre os produtos do cotidiano. A partir desta experiência, bordamos muitas pimentas em aventais, sacolas e embalagens de tecido, mas a anedota por trás desta série de pimentas é que a ideia inicial era que bordássemos receitas usando temperos, frutos, cereais, no entanto, as discussões sobre as receitas se tornaram tão intensas, uma vez que cada uma tinha uma receita e a sua receita era melhor que a outra que decidimos bordar só as pimentas.

Imagem 4: São João 
Este projeto esteve atuante entre 2016 a 2018. Conforme as tarefas foram se complexificando, uma série de questões surgiram, com as quais nem eu e nem as Bordadeiras da Ilha estávamos preparadas para lidar: a dificuldade em consolidar a Associação se ampliava diante da burocracia e dos custos que não tínhamos como cobrir; as oficinas de educação patrimonial, prósperas no início, tornaram-se cansativas. E, definitivamente, nossa limitação técnica para treinar novos pontos, aliás, a ideia em ampliar a oferta de peças, necessitaria de outros profissionais como designer, de costureiras ou, até mesmo, de comerciantes para favorecer circulação e venda, para, assim, tornar o negócio sustentável e autogestionável.

Realizar oficinas, discutir as perspectivas do patrimônio, entender as narrativas sobre as histórias e as memórias por meio dos bordados era possível, mesmo com um certo custo com materiais utilizados nos encontros. No entanto, uma vez que encomendas entraram em pauta, um outro investimento financeiro e de tempo era necessário. Por fim, o apoio ao projeto pela UFRB se restringia ao investimento em bolsas para alunos, que foram paulatinamente reduzidas, tornando inviável seguir com o projeto sem auxílio de estudantes. Além disso, a universidade não ofertava uma incubadora de negócios sociais em Santo Amaro, o que poderia ter minimizado essas dificuldades. Infelizmente, o projeto precisou ser suspenso até nos realinharmos novamente, o que espero que ocorra em um futuro não tão distante.

Conforme via o engajamento daquelas mulheres, empolgava-me com a movimentação e com as possibilidades daquilo que imaginava ser o sucesso pleno do projeto, no entanto, observando criticamente e com a distância do tempo, percebo que estava em um movimento pendular daquilo que Gadotti (2017) abordou como as duas vertentes da extensão universitária. Segundo o educador, há uma vertente mais assistencialista que entende a extensão por meio de uma "transmissão vertical do conhecimento, serviço social, desconhecendo a cultura e o saber popular" (Gadotti, 2017, p. 2). Fato é que, por mais que eu tentasse escapar, eu me vi, muitas vezes, querendo pautar o que eu entendia por patrimônio e fomentar o desejo delas montarem uma cooperativa e obter sucesso no mercado dos bordados.

Em outros momentos, que se tornaram mais frequentes com o passar dos meses, o pêndulo alterava seu ponto e eu percebia que a extensão estava mais próxima da ideia freiriana de "comunicação de saberes" (Gadotti, 2017). Assim, era possível romper hierarquia e papéis, permitindo-me transformar e repensar muitas coisas: minha inserção na comunidade santamarense, a pesquisa com os bordados, os conteúdos a serem trabalhados, formalmente, em sala de aula com meus alunos, entre tantos outros temas. Talvez, o tempo e os conflitos eminentes foram me ensinando o que é a extensão universitária.

Ao viver uma prática extensionista, com o tempo, passei a caminhar em uma vereda convergente: do mesmo modo em que me punha diante de uma pauta antropológica - percepção dos espaços, saber-fazer e aprendizado no corpo, aproximação com as redes de sociabilidade, memória e esquecimento -, conviver com as bordadeiras me levou a outros níveis de experiência etnográfica e de posicionamento docente: 
(...) a Extensão, como a raiz do próprio nome indica, existe para trazer tensão a um campo domesticado, qual seja, o do saber acadêmico institucionalizado: identificar a tensão gerada pela censura e a exclusão de saberes não legitimados; formular projetos; em parcerias com os grupos e comunidades detentores desses saberes; e, assim, ampliar o universo de reflexão acadêmica, dissolvendo de um modo positivo e enriquecedor a tensão excludente inicial (gerando, de fato, uma ex-tensão) (Carvalho, 2004, p. 21).

Vista desta forma, a extensão universitária atua como conexão, em um caminho de mão dupla, no qual a sociedade se beneficia e é beneficiária da universidade, uma vez que aproxima realidades várias, ampliando questões e possibilidades, renovando saberes e conteúdos a fim de uma "forma de realimentar a imaginação interna ao nosso mundo, dela profundamente carente" (Carvalho, 2004, p. 7).

Ainda que assumindo um certo tom de lamento pelo projeto da associação não ter se efetivado como imaginávamos, sonhar em construir algo juntas, refletindo em parceria, assumindo riscos, errando e acertando trouxe uma sensação de troca constante, completamente diferente da relação entre pesquisador/pesquisado, professor/aprendiz. Eram outros papéis que, enfim, regularam novas perspectivas de relacionamento.

Estamos diante de um projeto acadêmico que consolida o tripé do ensino superior e pode ser, sobretudo, um espaço de aprendizagem interdisciplinar, indissociável da pesquisa, por meio da aproximação com a comunidade na qual a universidade está inserida. Fato é: a experiência com a extensão não pode estar fincada nas lógicas de assistência social - algo que entendo possível como uma intervenção de cunho e de circunstâncias pontuais - e, nem tampouco significa tratar a comunidade como objeto de pesquisa, o qual se descola dos sujeitos ali implicados. Na verdade, é exatamente o oposto. É saber que o lócus do saber não é a universidade e a comunidade não é um repositório de temas; todavia, é neste ambiente relacional entre comunidade e universidade que se propõe um diálogo de curiosidades, interesses e empenho mútuos.

A extensão revela o compromisso social e o papel da universidade frente aos direitos sociais, à cidadania e aos saberes não elitistas ou institucionalizados que são, muitas vezes, deixados alheios à vida universitária. E, neste exercício político, o foco deve ser o de princípios, critérios e demandas dos próprios grupos. É preciso estar ciente que, neste lugar de engajamento, a prática extensionista altera a vida das comunidades envolvidas: locais e/ou acadêmica. Carvalho (2004) acerta ao afirmar que o lugar da extensão é radical, crítico, dedicado ao valor de troca e à dádiva. Por isso, é preciso um processo reflexivo e dialógico, desde o planejamento, passando pela execução até a avaliação de uma atividade, realizados pelos sujeitos autores dos processos, em uma parceria equalizada e com objetivos comuns. Reafirmo: todos os envolvidos são parceiros.

Há um dado interessante na produção de bordados e que somente pude entender pelas projeções intelectuais que meus colegas, certa feita, me fizeram sobre o bordar na Ilha do Dendê. Estava apresentando o "Bordando a Cidade" em uma 
destas reuniões que preenchem a vida dos professores na universidade pública. Apresentei as atividades e todos se mostraram interessados, elogiando o projeto e os bordados. Alguns, muito bem intencionados, se mostravam felizes pela minha investida comunitária e estavam interessados, especificamente, nos teores das conversas que tínhamos enquanto bordávamos coletivamente. As questões que me fizeram foram pontuais e precisas: meus colegas queriam saber se bordávamos sentadas em roda, se as mulheres contavam acerca da violência e da pobreza do bairro, se eu me emocionava nas reuniões. Eu não havia parado para pensar nestes conteúdos até então.

$\mathrm{Na}$ época, trazia algumas questões sobre o bordado que, desde o doutorado, permaneciam em aberto. Foram anos dedicados a entender como se produz o bordado e eu nunca tinha conseguido entender o que elas queriam dizer quando me falavam sobre deixar a alma tranquila e fazer silêncio - até porque, o bordado de Caicó, que estudei no doutoramento, é um bordado realizado à máquina, portanto, tem barulho (Brito, 2010). No entanto, foi a partir das perguntas de meus colegas é que comecei a perceber que aqueles bordados caicoenses guardavam um silêncio latente ainda que dentro do barulho nos quais eram produzidos, e o som da máquina funcionaria como uma espécie de redoma aos barulhos externos.

Quando começamos a bordar na Ilha do Dendê, o barulho era uma constante. Conforme fomos aprendendo as técnicas, o silêncio foi se tornando constante. A voz, quando se ouvia, era sempre baixa. As conversas tinham tons gentis, ainda que tratando de temas que doem como as injustiças, os lutos, os medos, os sonhos. Falávamos? Sim, o que precisava ser dito. O foco estava no projeto em questão uma toalha, um lenço, um jogo americano, um guardanapo, uma bolsa -, a construção conjunta, a concentração, o ato de se acalmar para pensar no próximo ponto, no próximo passo, em quem está ao lado. Estávamos diante de uma outra forma de se relacionar que o ofício e a técnica proporcionam. Ali vivíamos uma ação coletiva de parceria, de apoio e de caminhar conjunto.

Foi bordando que vislumbrei tanto os modelos de sociabilidade feminina quanto a forma de agir no mundo que eu buscava naquele bairro. Foi, então, que entendi o que era uma solidariedade fundamentada no afeto e por meio de ações que facilitam o caminhar conjunto. Uma ajudava a outra a completar uma peça da mesma forma que ajudava a olhar o filho brincando na rua. Elas conversavam temas importantes, mas de uma forma que não constrangesse a outro porque os laços de vizinhança e de trabalho se sobrepunham ali. Elas já tinham alguns vínculos, mas bordar juntas aprofundou estes vínculos. $\mathrm{E}$ eu, que não tinha vínculo algum, comecei a me sentir parte de uma comunidade. Sou, do mesmo modo, alguém que borda, que vende, que carrega sacolas com tecidos, que reclama do preço das linhas, que fica brava quando perde a agulha. Aprendi a estar em Santo Amaro e a quem buscar quando preciso de ajuda. 


\section{Considerações finais (ou entender-se ouriçada)}

Concordo com Carvalho (2004) quando afirma que é necessário fomentar uma universidade que resista ao eurocentrismo, ao racismo e à mercantilização. No entanto, mesmo com as políticas do Reuni, brevemente apresentadas no início do texto, podemos observar que este desejo de inclusão social, étnica e racial no ensino superior brasileiro acabou por incluir apenas os melhores e mais adaptados alunos das escolas públicas, ou seja, só atingimos uma parcela ínfima dos pretos e dos pobres. Há uma exclusão objetiva e subjetiva no acesso à universidade. Definitivamente, a comunidade não está na Universidade e, talvez, a extensão universitária seja um caminho para uma presença efetiva e coerente com a vida.

Acredito, piamente, que a internalização da educação superior no Brasil é uma política correta, inclusiva e revolucionária. É uma chance única de produzir conhecimento, abrindo mão de ranços e picuinhas, e fazendo ciência com o pé no chão, no nosso chão, ao lado da nossa gente. Neste contexto e ligadas aos meus interesses, as questões relacionadas ao patrimônio, usualmente objetificado e reificado pelas políticas públicas, emergem aqui como uma voz potente sobre o direito à memória e sobre quais as narrativas que escolhemos para contar. Assim, se as expressões culturais santamarenses são importantes, igualmente importantes o são as árvores, os rios, as conversas. É a sua gente que deve nos mover.

Houve uma tarde que, retornando a Salvador, animada, contava a um colega sobre a experiência com a extensão. Naquele dia, eu estava particularmente feliz. Entre outras coisas, relatava como a experiência com a extensão havia me aberto para um novo tipo de relacionamento, distinto daqueles que consegui atuando em outras pesquisas, inclusive entre aquelas que tinha sido profundamente afetada pelo campo. Eu dizia que, muitas vezes, ficava nervosa, irritada, depois, emocionada com as conquistas, até mesmo, arrepiada. Contei-lhe que nunca sabia o que aconteceria em cada uma das reuniões, mas que esperava ansiosamente os nossos encontros semanais. Ao final desta conversa, ele me disse: "acho que você está fazendo uma antropologia ouriçada”. Rimos. Concordei. Sem dúvidas, foi a extensão universitária quem colocou essa "minha" antropologia em movimento e arrepiada, tal qual um ouriço.

Este relato começa com festas, mudanças, esperanças. No entanto, agora, escrevo este artigo, com saudade de bordar com as mulheres da Ilha do Dendê, e em meio a situações assustadoras. A NCovid 19 se transformou em uma pandemia que tem escancarado mazelas sociais. Há meses distantes de estudantes e do projeto de extensão, os dias se alternam entre desânimo e esperança. A universidade pública tem sido sufocada por cortes, críticas e perseguições midiáticas que nos levam a investir mais tempo nos protegendo do que produzindo ciência e ensino com relevância para nossas comunidades. Santo Amaro, enquanto isso, dribla a miséria, a doença, e seu temor mais severo: uma possível ameaça de devastação ambiental.

Ao concluir este depoimento, em julho de 2020, o atual prefeito da cidade afirmou, publicamente e por meio das redes sociais, que retirou a doação do terreno 
da Tarzan e o ofertou para uma indústria química paulista, reavivando nossos medos mais antigos de uma nova onda de poluição ambiental na cidade. Em troca de possíveis postos de trabalho, corremos o risco de entregar o sonho do nosso campus e não temos sequer garantias de que a comunidade vai ter o direito à vida.

Recebido: 24/07/2020

Aprovado: 24/08/2020 


\section{Referências}

AGIER, M. Antropologia da cidade: lugares, situações, movimentos. São Paulo: Terceiro Nome, 2011.

BRASIL/SESU. Referenciais Orientadores para os Bacharelados Interdisciplinares e Similares. Brasília: MEC/SESu, 2010. Documento elaborado pelo Grupo de Trabalho instituído pela Portaria SESu/MEC n. 383, de 12 de abril de 2010. Disponível em: http:// portal.mec.gov.br/conselho-nacional-de-educacao/323-secretarias-112877938/ orgaos-vinculados-82187207/17649-referenciais-orientadores-para-os-bacharelados-interdisciplinares-e-similares. Acesso em: 09 jun. 2020.

BRITO, T. F. S. Bordados e bordadeiras: um estudo sobre a produção artesanal de bordados em Caicó (RN). Tese (Doutorado em Antropologia Social) - Universidade de São Paulo, São Paulo, 2010.

BRITO, T. F. S. De artesã à empresária: uma reflexão sobre os discursos de formação empresarial das artesãs de linhas e agulhas. In: ALVES, R. C. D. P; NASCIMENTO, C. O. C. Formação cultural: sentidos epistemológicos e políticos. Cruz das Almas; Belo Horizonte, Editora UFRB; Fino Trato, 2016. p. 279-295.

ALVES, R. Conversa com quem gosta de estudar. São Paulo: Cortez, 1980.

CARVALHO, J. J. A prática da extensão como resistência ao eurocentrismo, ao racismo e à mercantilização da universidade. Brasília: Editora da UnB, 2004. Disponível em: http://dan.unb.br/images/doc/Serie363empdf.pdf. Acesso em: 19 set. 2020.

CORBETT, S. How to be a craftivist: the art of gentle protest. London: Unbound, 2017.

D’AMBROSIO, O. Arquitetura espontânea. Disponível em: http://oscardambrosio.com. br/textos/46/arquitetura-espontanea. Acesso em: 4 nov. 2020

FRAGA FILHO, W. Encruzilhadas da Liberdade: histórias de escravos e libertos na Bahia (1870-1910). Rio de Janeiro: Civilização Brasileira, 2014.

GADOTTI, M. Extensão universitária: para quê? São Paulo: Instituto Paulo Freire, 2017. Disponível em: https://bit.ly/3mtsUYL. Acesso em: 20 set. 2020.

IBGE - Instituto Brasileiro de Geografia e Estatística. Santo Amaro - Bahia. 2. ed. Rio de Janeiro: IBGE, 1968. Disponível em: https://biblioteca.ibge.gov.br/visualizacao/ periodicos/113/col_mono_n394_santoamaro_2ed.pdf. Acesso em: 30 jun. 2020.

IPHAN - Instituto do Patrimônio Histórico e Artístico Nacional. Dossiê para Instrução de Registro Bembé do Mercado. Brasília: IPHAN, 2019. Disponível em: http://portal. iphan. gov.br/uploads/ckfinder/arquivos/Dossie_Bembe_do_Mercado. pdf. Acesso em: 11 jul. 2020.

LOSE, A. D.; MAZZONI, V. S. Manuscritos do antigo Recolhimento dos Humildes: documentos de uma história. Salvador: Memória e Arte, 2016. (Col. Uma história escrita à mão, v. II).

MARENGO, S. N. Santo Amaro-BA: um lugar de muitos lugares. Tese (Doutorado em Geografia) - Universidade Federal da Bahia, Salvador, 2016.

MENDES, R. Prefeitura de Santo Amaro doa terreno para construção de novo campus da UFRB. [Entrevista concedida a] Alissandro Lima. Reverso Online, Cachoeira, 13 mar. 2013. Disponível em: https://bit.ly/3kAuoi1. Acesso em: 11 jun. 2020.

PEDREIRA, P. Documentos históricos de Santo Amaro. Santo Amaro: Imprensa Oficial, 1973. p. 4-7. Disponível em: https://adrianoportela.files.wordpress.com/2016/06/ata-da-vereac3a7c3a3o-de-14-de-junho-de-1822.pdf. Acesso em: 19 jun. 2020. 
Thaís Brito

ROSSI, A. A arquitetura da cidade. São Paulo: Martins Fontes, 2001.

SACRAMENTO, C. F. do; NASCIMENTO, D. M. C.; COSTA, M. E. P. Subsídio para o Plano de Desenvolvimento Sustentável Municipal de Santo Amaro - Bahia - Bairros de Gericó e Ilha do Dendê. Salvador: Ministério do Meio Ambiente (MMA); Secretaria de Recursos Hídricos (SRH); Universidade Federal da Bahia (UFBA), 1999. Disponível em: http:// www.subaegeo.ufba.br/pdf/Adote\%20uma\%20Bacia.pdf. Acesso em: 11 jul. 2020. 